\title{
MODS and the
}

Digital Repository of Ireland

$\operatorname{dri} \tilde{\sim}^{\infty}$ 
Contributors from the Digital Repository of Ireland Metadata Taskforce:

Dr. Marta Bustillo, Assistant Librarian, Metadata Cataloguer, Trinity College Dublin

Rebecca Grant, Digital Archivist, Royal Irish Academy

Dr. Stuart Kenny, Software Engineer, Trinity College Dublin

Dr. Agustina Martínez García, Postdoctoral Researcher, Maynooth University

Charlene McGoohan, Requirements Manager, Maynooth University

Dr. Rósmáire Ní Cholla, Digital Curator, National University of Ireland, Galway

Dr. Aileen O'Carroll, Policy Manager, Maynooth University

Jenny O'Neill, DRI Data Curator, Trinity College Dublin

Sinéad Redmond, Software Engineer, Maynooth University

Dr. Sharon Webb, DAH PhD Programme Knowledge Transfer Manager, Royal Irish Academy

Edited by Dr. Marta Bustillo and Dr. Agustina Martínez García

First published in 2016 by the Royal Irish Academy

(c) Maynooth University, Trinity College Dublin, National University of Ireland, Galway,

and the Royal Irish Academy

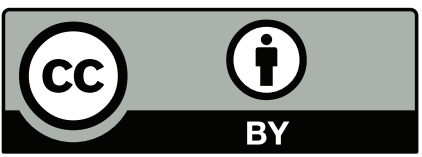

This work is licensed under a Creative Commons Attribution 4.0 International Licence.

When citing or attributing this report please use the following: Bustillo, M., Grant, R., Kenny, S., MartínezGarcía, A., McGoohan, C., Ní Cholla, R., O'Carroll, A., O’Neill, J., Redmond, S. and Webb, S. (2016) MODS and the Digital Repository of Ireland (M. Bustillo, A. Martínez-García, Eds.). Maynooth: Maynooth University; Dublin: Trinity College Dublin; Dublin: Royal Irish Academy; Galway: National University of Ireland, Galway. DOI: http://dx.doi.org/10.3318/DRI.2016.1

DRI may update its guidelines documentation from time to time as the Repository develops. Please ensure that you are using the most up-to-date version of our documentation by checking our DRI Publications page. 


\section{Foreword}

The Digital Repository of Ireland (DRI) has been built to serve the digital preservation needs of the social sciences and humanities in Ireland, by combining a grassroots approach to community requirements with extensive research into international best practices. Our work on metadata began in 2011 with a broad and deep consultation of key institutions across Ireland to understand existing archival practices and metadata usage, and we are grateful to these institutions for their expertise and engagement with our research. Following this study, we conducted research into international best practices in digital archiving. The results of this foundational work can be found in Digital Archiving in Ireland: National Survey of the Humanities and Social Sciences (2012) ${ }^{1}$ and Caring for Digital Content: Mapping International Approaches (2013). ${ }^{2}$ In 2013 we established a multidisciplinary task force to consolidate our national and international findings, and to begin the process of developing guidelines for metadata creation for different data types and sectors within the broad realm of social and cultural data. Our first set of guidelines, Dublin Core and the Digital Repository of Ireland were published in 2015, followed by Qualified Dublin Core and the Digital Repository of Ireland.

The purpose of publishing this series is both practical and aspirational. On the one hand, the documents provide guidelines for preparing metadata for ingestion into the Digital Repository of Ireland for the mostly widely used metadata standards in our community. On the other hand, we hope that their reach will go beyond DRI, providing the basis for a standardised approach to metadata preparation in Ireland's social sciences and humanities domains. If we adopt common standards, and approach metadata preparation in similar ways, we will create greater interoperability between our data collections, which will in turn enable improved and enhanced discovery and richer contextualised crosscollection narratives

I would like to express our deepest thanks to all the individuals and institutions who have collaborated and communicated with us in developing these guidelines, and who have provided feedback on their implementation. We welcome you to test this latest set of guidelines, and equally welcome and encourage any feedback you have to share.

Dr. Natalie Harrower

Acting Director, Digital Repository of Ireland

\footnotetext{
1 http://dx.doi.org/10.3318/DRI.2012.1

2 http://dx.doi.org/10.3318/DRI.2013.1
} 


\section{Acknowledgements}

We would like to thank the following individuals who gave so generously of their time:

Jan Ashton, Service Development Analyst, National Bibliographic Service, British Library

Audrey Drohan, Senior Library Assistant, James Joyce Library, University College Dublin

Dr. John Howard, Librarian, University College Dublin

Jennifer Liss, Head, Monographic Image Cataloguing, Indiana University Libraries

Lisa McAulay, Librarian for Digital Collection Development, UCLA Digital Library Program

Amelia Mowry, Metadata \& Discovery Services Librarian, Wayne State University, Detroit, Michigan

Orna Roche, Assistant Librarian, Research \& Innovation/Collection Services, James Joyce Library,

University College Dublin 


\section{Introduction}

These guidelines are aimed at anyone using the MODS metadata standard to prepare content which will be deposited with the Digital Repository of Ireland ("the Repository"). These metadata guidelines do not contradict, or indeed replace, the MODS metadata standard, but should be used in tandem with it to ensure that the metadata can be ingested and searched in the Repository.

Although MODS 3.6 has now been approved by the MODS Editorial Committee, these guidelines refer to MODS 3.5 which will continue to be supported by the Repository. These guidelines may be updated to reference MODS 3.6 when further guidance from the Library of Congress becomes available.

By following these guidelines, which include mandatory and recommended elements for ingestion of metadata into the Repository, you will be making your collections more easily searchable in the Repository, and cross-searchable with other DRI collections.

\section{Mandatory and Recommended Elements}

Data must be provided for Mandatory elements to enable metadata to be ingested by the Repository; metadata will be automatically rejected by the system if Mandatory elements are not included. Recommended elements do not have to be included, but DRI strongly advises that they are completed if possible in order to facilitate searching. The remaining MODS elements are Optional. All submitted elements, whether Mandatory, Recommended or Optional, will be stored and available in the Repository.

\section{What to Catalogue}

DRI recommends following the "one to one" principle of Dublin Core: the principle whereby related but conceptually different entities, for example a painting and a digital image of the painting, are described by separate metadata records ${ }^{3}$. Metadata for a given object can refer to either the physical object or to the digital surrogate, but the information entered should not be a mixture of both.

\section{Controlled Vocabularies}

Controlled vocabularies are recommended in order to enhance the Repository's search function. Although specific controlled vocabularies are recommended in the tables below, they are not mandatory.

${ }^{3}$ http://wiki.dublincore.org/index.php/Glossary/One-to-One_Principle, last accessed 10 December 2015. 


\section{Metadata Object Description Schema (MODS)}

MODS records for ingestion in DRI should be encoded in XML using the MODS XML Schema (XSD) in its version 3.5.4 As the MODS schema supports the use of a wrapper for grouping together a set of MODS records (via the <modsCollection> element), two different types of XML-encoded MODS records are supported for ingest. The first of these is a collection of MODS records, encoded as a single XML file. This type of XML would look as follows (with relevant header lines shown in bold):

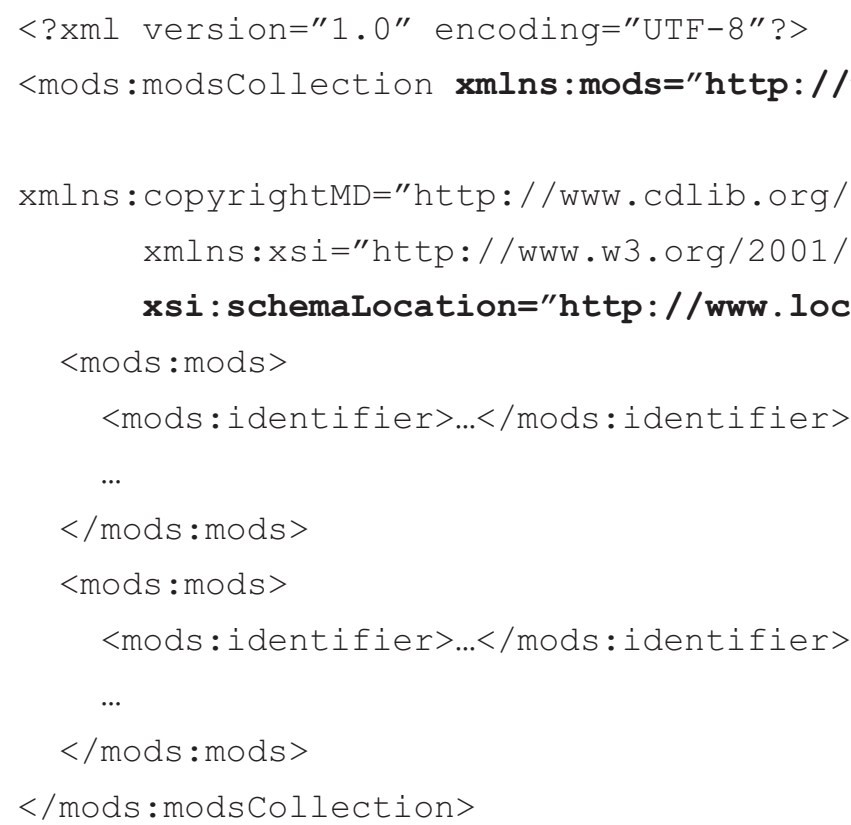

If encoding the MODS records individually, each of the records would look like this:

<?xml version="1.0" encoding="UTF-8"?>

$<\operatorname{mods}: \operatorname{mods}$ xmlns:mods="http://www.loc.gov/mods/v3"

xmlns: copyrightMD="http://www.cdlib.org/inside/diglib/copyrightMD" xmlns:xsi="http://www.w3.org/2001/XMLSchema-instance" xsi:schemaLocation="http://www. loc.gov/mods/v3 mods-3-

\section{$5 \cdot \mathbf{x s d}^{\prime \prime}>$}

$<$ mods:identifier $>$... $</$ mods:identifier $>$

$\ldots$

$</$ mods:mods $>$ 
Note: Please note that the system is expecting qualified XML for ingest, that is, namespace prefixes must be used throughout the XML. The following namespace prefixes are required:

- mods for the MODS namespace (xmlns:mods="http://www.loc.gov/mods/v3" declaration in the XML root element)

- copyrightMD for the Copyright Metadata Schema ${ }^{5}$ namespace

(xmlns: copyrightMD="http://

www.cdlib.org/inside/diglib/copyrightMD" declaration in the XML root element)

\section{Ingesting into the Repository}

MODS metadata is ingested into the Repository in XML format. In order to match the metadata with its file, the metadata file and digital asset file should use the same filename, e.g. object1.xml and object1.tif

If there are multiple digital assets associated with the metadata file, follow the filename with an underscore and an alphanumeric sequence, e.g. object2.xml with three digital asset files associated with it (object2_001.tif, object2_002.tif, object2_003.tif).

When ingesting a collection of MODS metadata records (as described in the previous section), in order to match the metadata with its digital asset file(s), the <mods : identifier $>$ element is used, with a value for the type attribute specified as "asset". For example, for a MODS record with digital asset files named object1_01.jpeg and object1_02.tiff, the $<$ mods: identifier> element would be as follows:

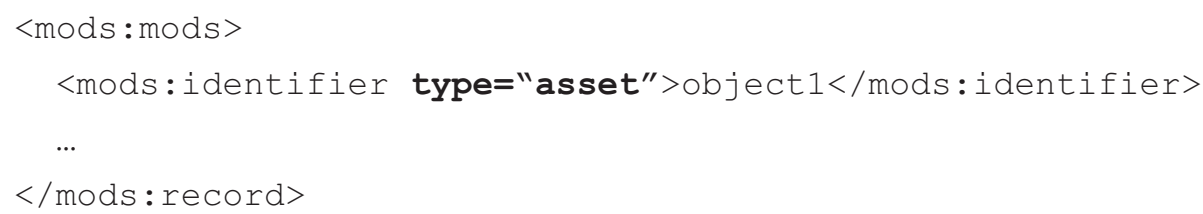

Please note that the value of $<$ mods: identifier $>$ does not include the file extension. Please see the DRI Resources page for further information on ingestion. ${ }^{6}$

${ }^{5}$ Rights Management Group - copyrightMD schema: http://www.cdlib.org/groups/rmg/, last accessed 10 December 2015

${ }^{6}$ http://www.dri.ie/resources-0, last accessed 10 December 2015 


\section{MODS Resources}

The MODS element set version 3.5 is currently available here. ${ }^{7}$

Guidance on using MODS for cataloguing is available here: Outline of Elements and Attributes in MODS Version 3.5.8

DRI also recommends that depositors follow the DLFIAquifer Implementation Guidelines for Shareable MODS Records in their implementation of the MODS standard: Digital Library Federation / Aquifer Implementation Guidelines for Shareable MODS Records Version 1.1 March 2009. ${ }^{9}$

\footnotetext{
7 http://www.loc.gov/standards/mods/v3/mods-3-5.xsd, last accessed 10 December 2015.

$8 \mathrm{http}: / /$ www.loc.gov/standards/mods/mods-outline-3-5.html, last accessed 10 December 2015.

${ }^{9} \mathrm{https} / / /$ wiki.dlib.indiana.edu/download/attachments/24288/DLFMODS_ImplementationGuidelines.pdf, last accessed 10 December 2015.
} 


\section{Table of mandatory and recommended elements, and suģgested controlled vocabularies/standards for DRI}

Element
Title
Name
Origin Info: Date Created

Origin Info: Date Issued

Origin Info: Date Captured

Abstract

Table of Contents

Note

\section{Access Condition}

Type of Resource

\section{Subtitle}

\section{Language}

Related item

Subject: Topic

\section{Subject: Name}

\section{Subject: Geographic}

Subject: Hierarchical Geographic

Subject: Geographic Code

\section{Subject: Cartographics}

Subject: Temporal

Identifier

Physical Description

Origin Info: Publisher

Obligation
Mandatory
Mandatory
Mandatory if Origin Info: Date
Issued and Origin Info: Date
Captured not used
Mandatory if Origin Info: Date
Created and Origin Info: Date
Captured not used
Mandatory if Origin Info: Date
Issued and Origin Info: Date
Created not used

Mandatory if Note and Table of

Contents not used

Mandatory if Abstract and Note not used

Mandatory if Abstract and

Table of Contents not used

Mandatory

\section{Recommended}

Recommended

Recommended

Recommended

Recommended

Recommended

Recommended

Recommended

Recommended

Recommended

Optional

Optional

Optional

\section{Controlled vocabulary}

No
Yes
Yes

Yes

Yes

No

No

No

No

Yes

No

Yes

No

Yes

Yes

No

Yes

Yes

Yes

Yes
14

\section{Page reference}

11

11

13

16

17

17

18

19

21

22

22

24

26

26

28

28

29

30

31 


\section{Sample DRI-compliant MODS XML record}

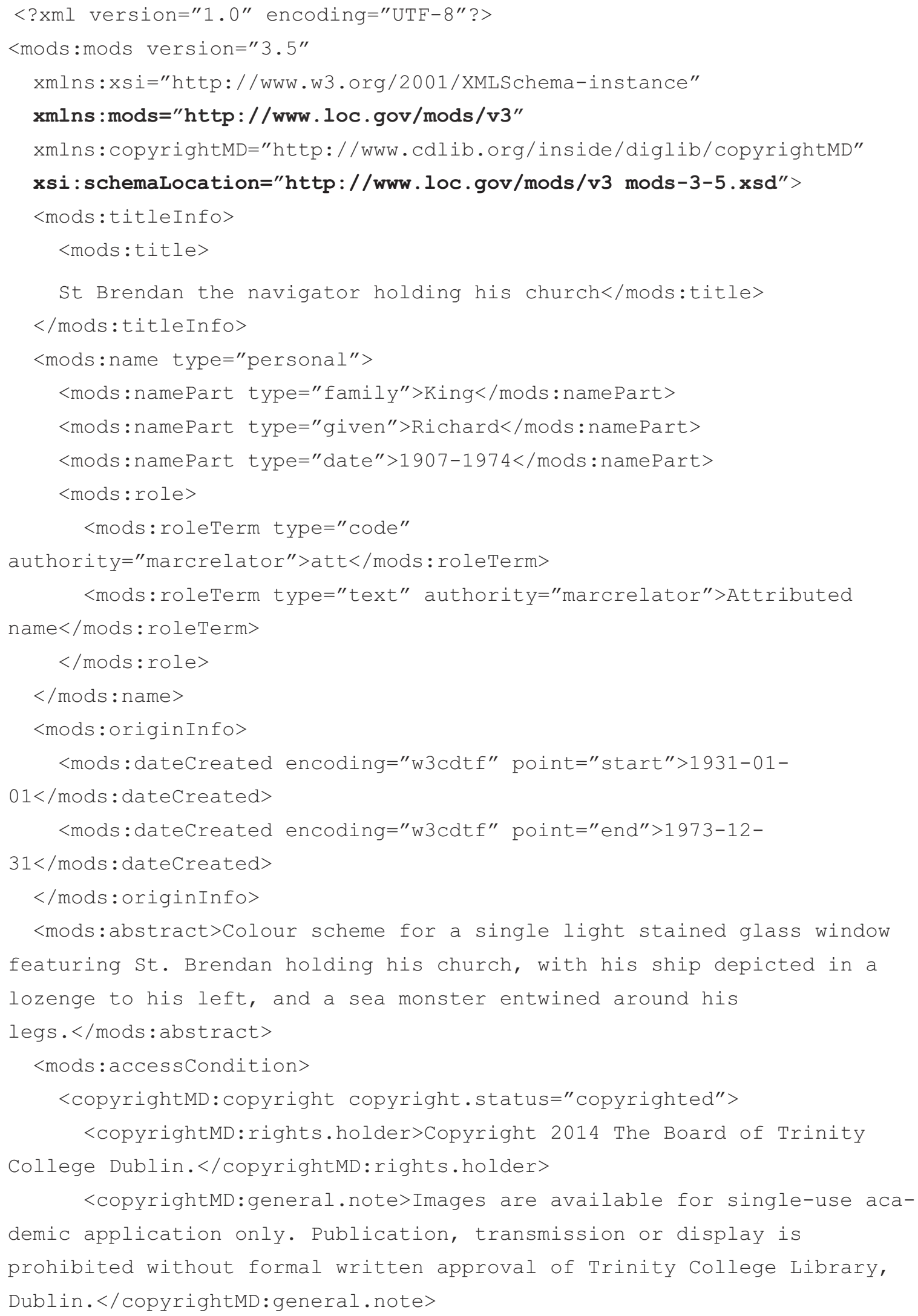




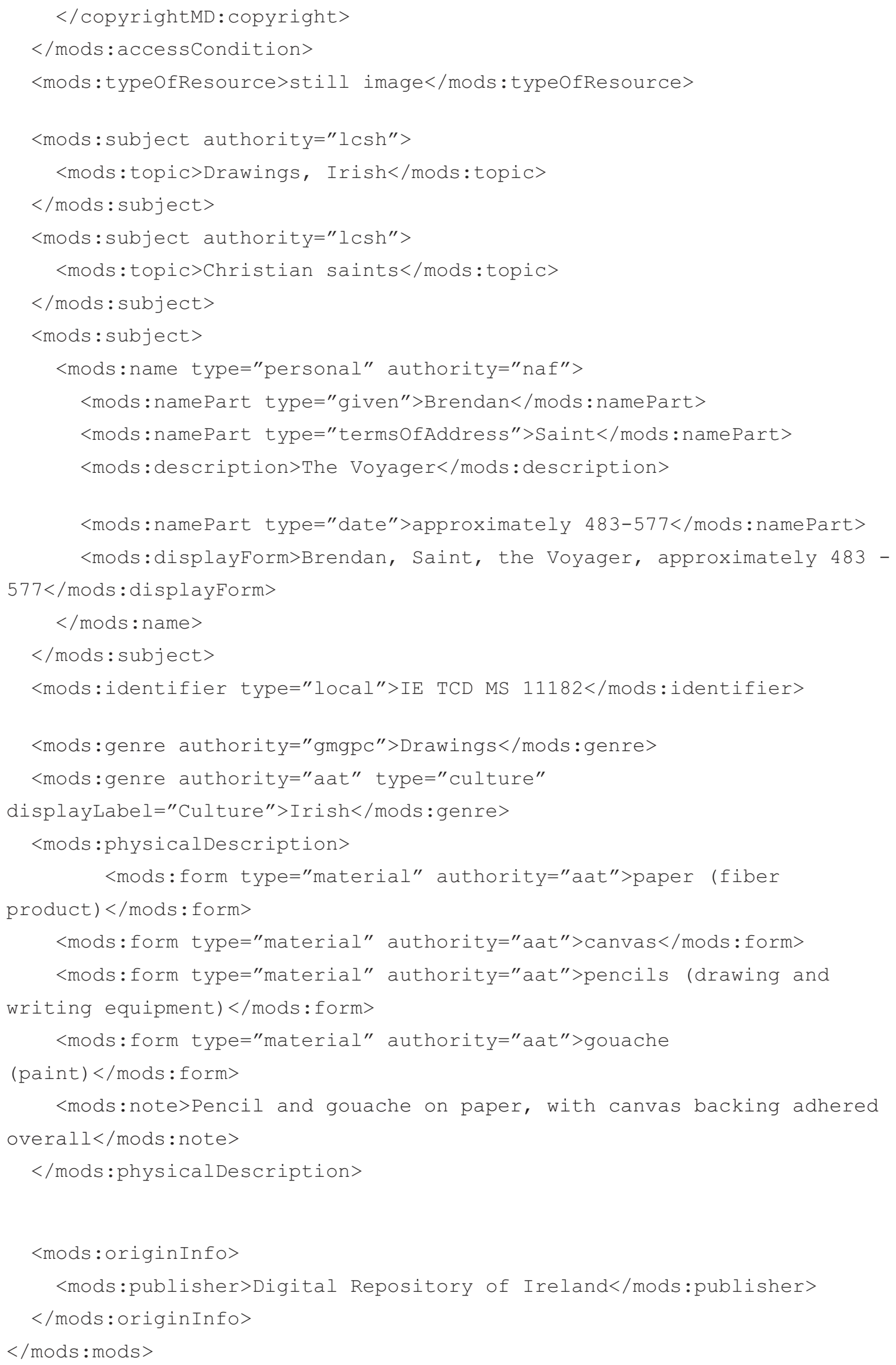




\section{Key to the Tables:}

Label

This is the name of the metadata field taken from the MODS

documentation, for example "Title Info".

Metadata Element

This is the namespaced, MODS XML encoding of the metadata

field; for example, <mods: titleInfo>

The elements described in these guidelines use the namespace

prefix mods

Definition

This is the formal definition of the element, taken from the MODS user guidelines.

Format of content This is the type of data entered in the metadata element, for example free text, or a suggested controlled vocabulary.

Obligation

This field details whether or not the element is a required field for ingest into the Repository. Elements are designated as either Mandatory or Recommended. Optional elements are not detailed in this document as they do not have DRI-specific recommendations associated with them.

Repeatable

This field details whether or not the metadata standard allows more than one use of the metadata field. For example, if it is possible to enter more than one Subject the element is repeatable, e.g.

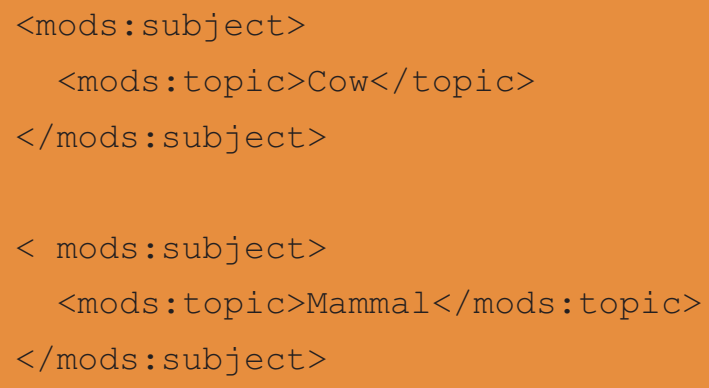




\section{MODS 3.5 Elements for DRI}

\begin{tabular}{|c|c|}
\hline Label & Title 10 \\
\hline \multirow[t]{3}{*}{ Metadata element } & $<$ mods:titleInfo> \\
\hline & $<$ mods:title/> \\
\hline & $</$ mods:titleInfos \\
\hline Definition & $\begin{array}{l}\text { A word, phrase, character, or group of characters that constitutes the chief } \\
\text { title of a resource, i.e., the title normally used when citing the resource. }\end{array}$ \\
\hline Format of content & Free text \\
\hline Obligation & Mandatory \\
\hline Repeatable & Yes \\
\hline \multirow[t]{3}{*}{ Values (examples) } & $<\operatorname{mods}$ :titleInfo> \\
\hline & $<$ mods: title>Ulysses</mods:title> \\
\hline & $</$ mods:titleInfos \\
\hline \multirow[t]{5}{*}{ Notes } & $\begin{array}{l}\text { The <mods: titleInfo> element is a container element that contains } \\
\text { all subelements related to title information, with their corresponding } \\
\text { attributes. Do not include punctuation intended to delineate parts of titles } \\
\text { that are separated into sub-elements of }<\text { mods: titleInfo>. }\end{array}$ \\
\hline & If multiple titles are recorded, repeat \\
\hline & $<\operatorname{mods}$ :titleInfo $><$ mods:title $>$ for each. $<$ mods: titleInfo $>$ \\
\hline & is also repeated for each type attribute value. \\
\hline & $\begin{array}{l}\text { The language of the title may be indicated if desired using the } x m I: \text { lang } \\
\text { or lang attributes. }\end{array}$ \\
\hline
\end{tabular}

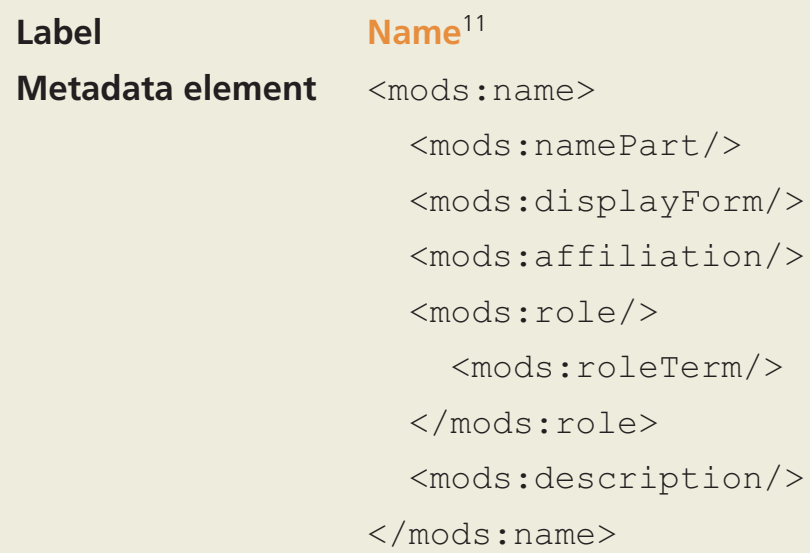

Definition

The name of a person, organisation, or event (conference, meeting, etc.) associated in some way with the resource.

$10 \mathrm{http}: / /$ www.loc.gov/standards/mods/v3/mods-userguide-elements.html\#title, last accessed 10 December 2015.

${ }^{11}$ http://www.loc.gov/standards/mods/userguide/name.html, last accessed 10 December 2015. 
Format of content Personal, family and corporate names should preferably be formatted according to the Irish Guidelines for Indexing Archives. ${ }^{12}$

\section{Obligation}

\section{Repeatable}

Values (examples)

$<$ mods: name $>$, <mods: namePart> and <mods: role> are Mandatory. All other subelements are Optional.

Yes

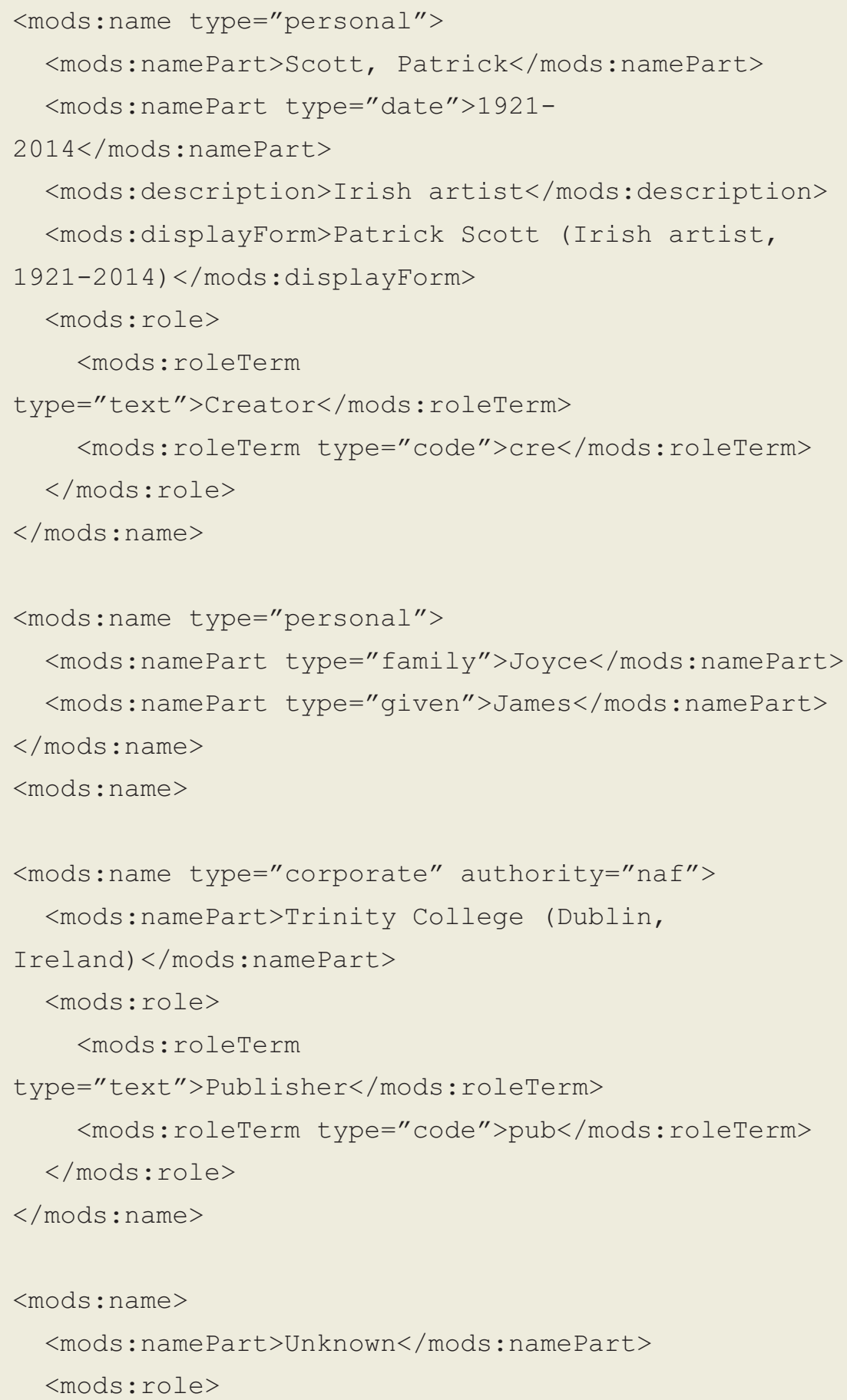

12 http://www.learnaboutarchives.ie/ learnabo/images/documents/ARAlndexing.pdf, last accessed 10 December 2015. 


\begin{tabular}{|c|c|}
\hline Notes & 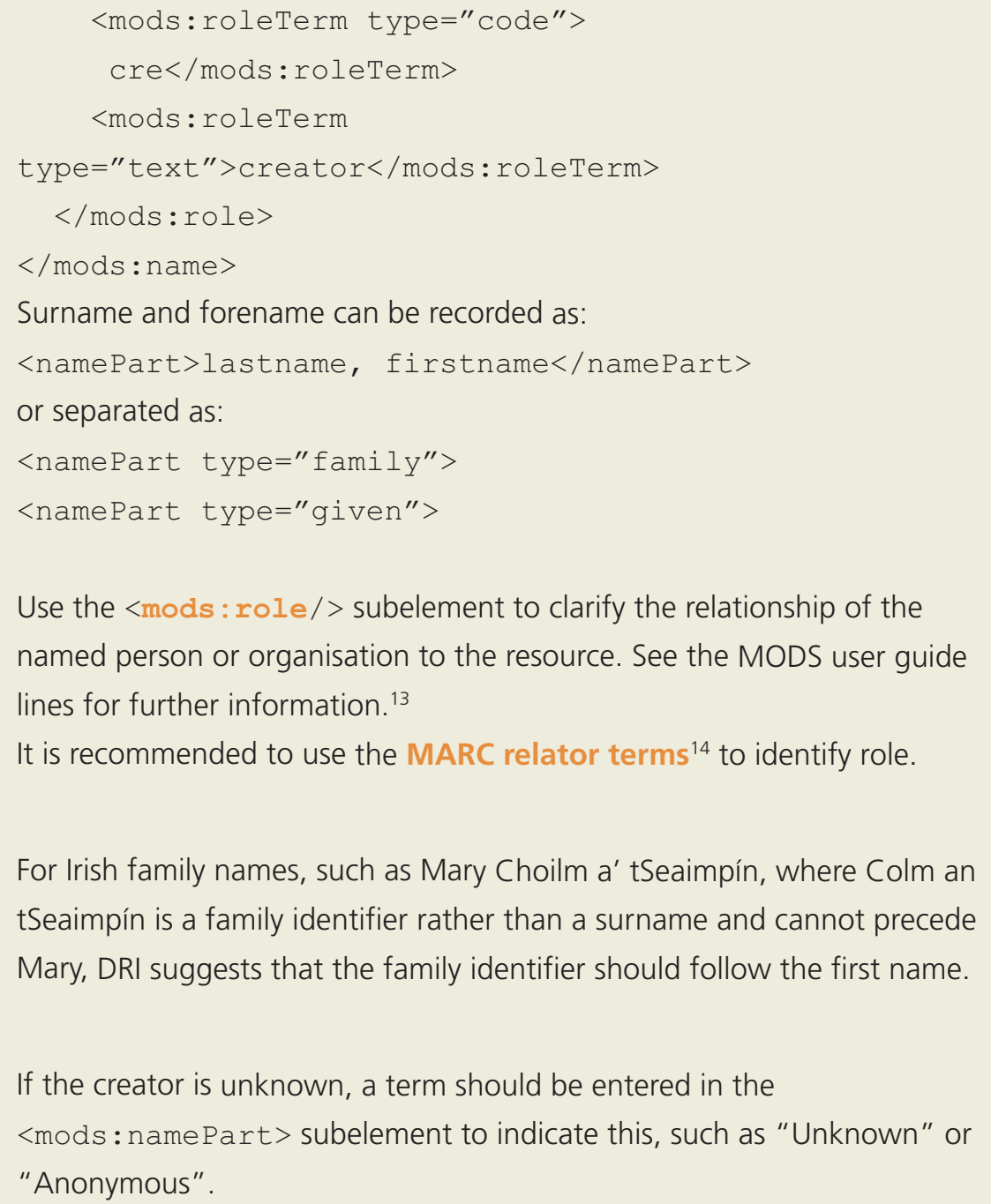 \\
\hline $\begin{array}{l}\text { Definition } \\
\text { Format of content }\end{array}$ & $\begin{array}{l}\text { Date Created } 15 \\
<\text { mods: originInfo> } \\
\quad<\text { mods: dateCreated> } \\
</ \text { mods: originInfo> } \\
\text { The date of creation of the original resource. } \\
\text { The content of the element is free text, but it should preferably be } \\
\text { formatted according to w3cdtf } 16 \text { or ISO } 8601 .{ }^{17} \text { If doing so, the attribute } \\
\text { "encoding" should be used, with a value of "w3cdtf" or "iso8601", } \\
\text { depending on the choice of encoding. }\end{array}$ \\
\hline
\end{tabular}

\footnotetext{
13 http://www.loc.gov/standards/mods/v3/mods-userguide-elements. html\#name, last accessed 10 December 2015.

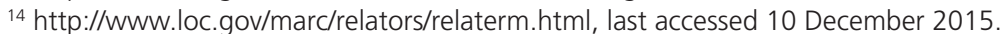

15 http://www.loc.gov/standards/mods/userguide/origininfo.html\#datecreated, last accessed 10 December 2015.

${ }^{16} \mathrm{http} / / / \mathrm{www} . w 3.0 \mathrm{rg} / \mathrm{TR} / \mathrm{NOTE}$-datetime, last accessed 10 December 2015.

$17 \mathrm{http}: / / \mathrm{www}$.iso.org/iso/home/standards/iso8601.htm, last accessed 10 December 2015.
} 
In DRI, dates not formatted according to w3cdtf or ISO 8601 will not be searchable by date range, nor displayed in the timeline visualisation tool. Attributes: See definitions for the attributes used throughout the MODS schema.

Obligation

Mandatory if Date Issued or Date Captured is not used.

Repeatable Yes

Values (examples)

$<$ mods:originInfo>

<mods: datecreated encoding="w3cdtf"

keyDate="yes">19721008</mods : dateCreated $>$

$</$ mods :originInfo>

Notes Examples of encoded dates that are searchable by date range:

Individual date:

$<$ mods:originInfo>

<mods: dateCreated encoding="w3cdtf">

20150323

$</$ dateCreated $>$

$</$ mods:originInfo $>$

Date range:

$<$ mods:originInfo>

<mods: dateCreated encoding="w3cdtf" point="start"> 2010

$</$ dateCreated $>$

<mods: dateCreated encoding="w3cdtf" point="end"> 2015

$</$ dateCreated $>$

$</$ mods:originInfo $>$

Attributes: See definitions for the attributes used throughout the MODS schema. ${ }^{18}$

\section{Label}

Date Issued ${ }^{19}$

Metadata element

$<$ mods:originInfo>

<mods: dateIssued>

$</$ mods:originInfo $>$

$18 \mathrm{http} / / / \mathrm{www}$. loc.gov/standards/mods/mods-outline.html, last accessed 10 December 2015.

${ }^{19} \mathrm{http}: / / \mathrm{www}$. loc.gov/standards/mods/userguide/origininfo.html\#dateissued, last accessed 10 December 2015. 
Definition

Format of content

\section{Obligation}

Repeatable

Values (examples)

Notes
Information about the date when the resource was published, released or issued.

The content of the element is free text, but it should preferably be for matted according to $w 3 \mathrm{cdtff}^{20}$ or ISO $8601 .{ }^{21}$ If doing so, the attribute "encoding" should be used, with a value of "w3cdtf" or "iso8601", depending on the choice of encoding.

In DRI, dates not formatted according to w3cdtf or ISO 8601 will not be searchable by date range, nor displayed in the timeline visualisation tool. Attributes: See definitions for the attributes used throughout the MODS schema.

Mandatory if <mods: dateCreated $>$ or <mods : dateCaptured $>$ are not used.

Yes

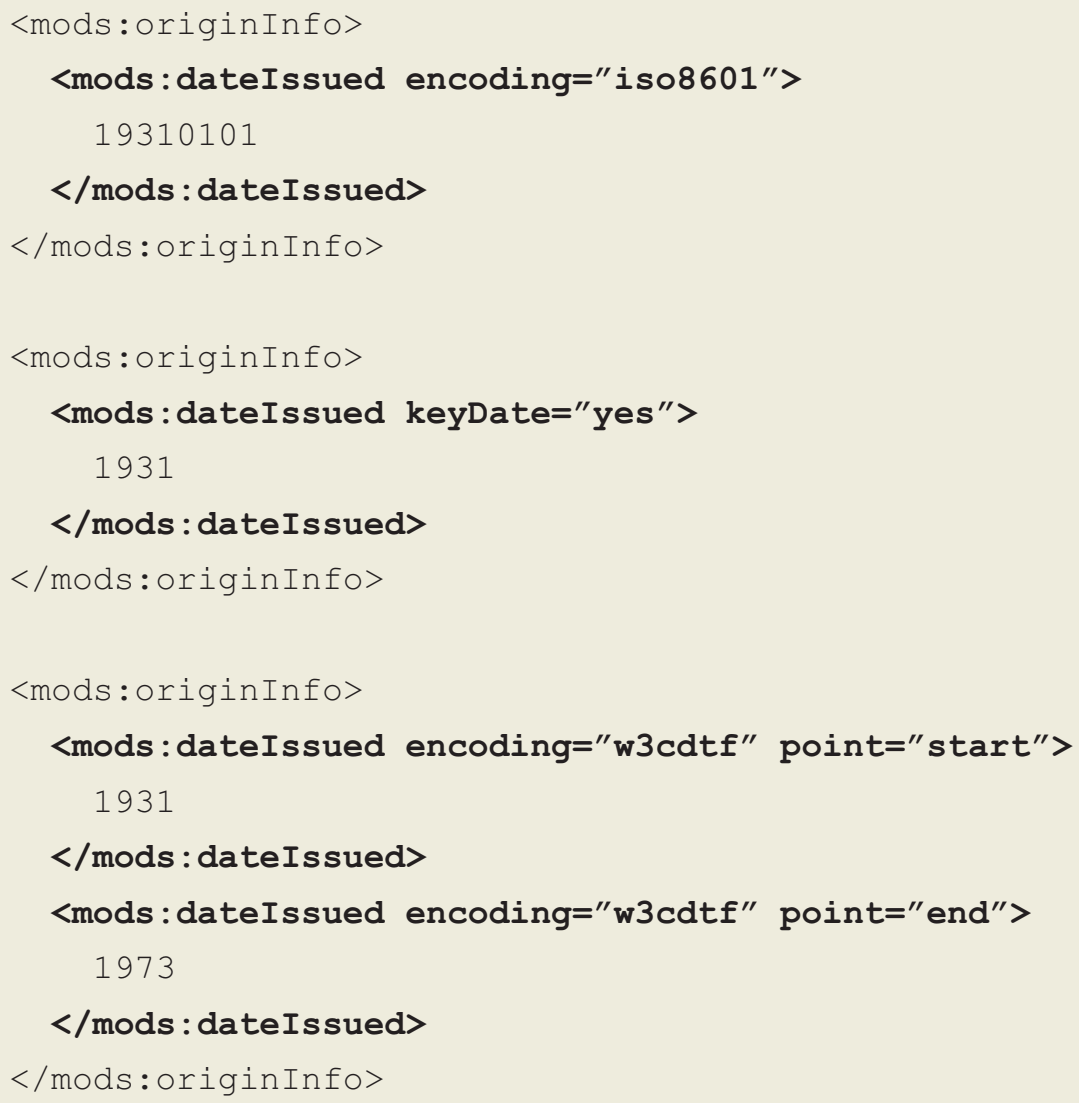

DRI has separate internal metadata that automatically stores and saves the date and time when the DRI record was created and published on the DRI repository.

This Date Issued element is more useful to describe issue/publication dates that are not handled by the DRI system, e.g. the actual issue/publication date of the item being described not DRI's digital representation of the item.

20 http://www.w3.org/TR/NOTE-datetime, last accessed 10 December 2015.

21 http://www.iso.org/iso/home/standards/iso8601.htm, last accessed 10 December 2015. 


\section{Label \\ Metadata element \\ Date Captured 22 \\ $<$ mods:originInfo> \\ <mods : dateCaptured> \\ $</$ mods:originInfo $>$}

Definition

Format of content

Obligation

Repeatable

Values (examples) taken schema 25 Yes

$<$ mods:originInfo>
The date on which the resource was digitised or a subsequent snapshot was

The content of the element is free text, but it should preferably be formatted according to $\mathrm{w} 3 \mathrm{cdtff}^{23}$ or ISO $8601^{24}$. If doing so, the attribute "encoding" should be used, with a value of "w3cdtf" or "iso8601", depending on the choice of encoding.

In DRI, dates not formatted according to w3cdtf or ISO 8601 will not be searchable by date range, nor displayed in the timeline visualisation tool. Attributes: See definitions for the attributes used throughout the MODS

Mandatory if <dateIssued $>$ or <datecreated $>$ is not used.

<mods : dateCaptured>2008-2014</mods : dateCaptured>

$</$ mods:originInfo $>$

<mods:originInfo>

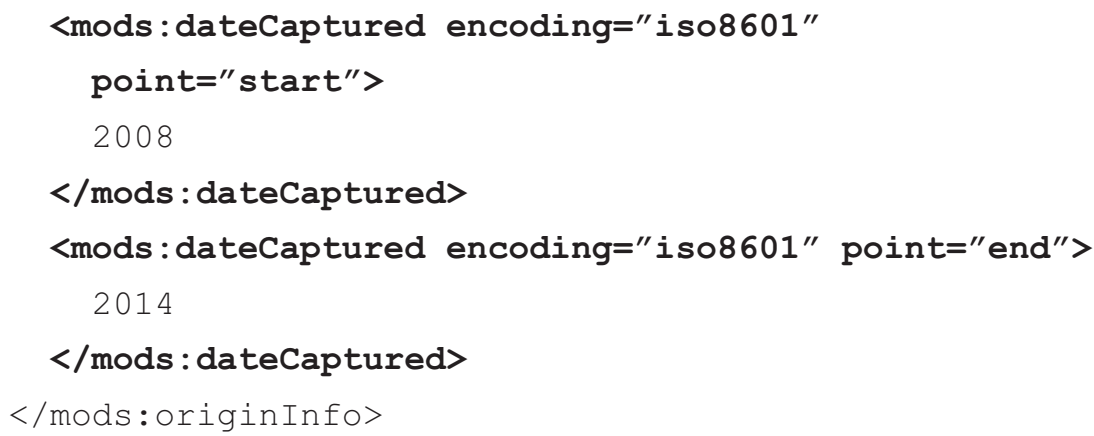

Notes

DRI has separate internal metadata that automatically stores and saves the date and time when the DRI record was created and published on the Repository.

This < datecaptured $>$ element is more useful to describe the actual date when the item being described was digitised, not DRI's digital representation of the item.

22 http://www.loc.gov/standards/mods/userguide/origininfo.html\#datecaptured, last accessed 10 December 2015.

$23 \mathrm{http}: / /$ www.w3.org/TR/NOTE-datetime, last accessed 10 December 2015

${ }^{24} \mathrm{http}: / /$ www.iso.org/iso/home/standards/iso8601.htm, last accessed 10 December 2015

25 http://www.loc.gov/standards/mods/mods-outline.html, last accessed 10 December 2015. 
Label

Metadata element

Definition

Format of content

Obligation

Repeatable

Values (examples)

Note
Abstract ${ }^{26}$

$<$ mods:abstract $>$

A summary of the content of the resource.

Free text

Mandatory if <mods: note/>, or <mods: tableofContents/>, or $<$ mods:physicalDescription $><$ mods: note/ $></$ mods:physical Description $>$ not used

Yes

$<$ mods:abstract $>$

A novel about the fictional character Leopold Bloom in turn of the century Dublin that mirrors the wanderings of the Ulysses epic.

$</$ mods:abstract $>$

For long abstracts, the Repository supports the inclusion of paragraphs and line breaks.

When creating XML metadata, \&\# $x \mathrm{D}$; may be used to create a carriage return, while $\& \# x A$; will create a line break. The inclusion of two carriage returns or line breaks consecutively, for example \&\#xA; \&\#xA; will create a paragraph break.

\section{Label}

Metadata element

Definition

Format of content

Obligation

Repeatable

Values (examples)

\section{Table of Contents ${ }^{27}$}

$<$ mods:tableofContents $>$

A description of the contents of the resource.

Use of <mods: tableofContents/> should be determined by the complexity of the resource and whether or not the information is readily available.

Free text; URI

Mandatory if $<$ mods: note $>$, or $<$ mods: tableofContents $>$, or $<$ mods:physicalDescription $><$ mods: note not used No

$<$ mods:tableofContents $>$

A suitable tone ; Left hand colouring ; Rhythm and accent ; Tempo ; Flexibility ; Ornaments - Sonata in D major, op. V, no. 1 / Corelli - Sonata in G minor

/ Purcell (with Robert Donington, gamba) - Forlane

from Concert royal no. 3 / Couperin

$</$ mods:tableofContents $>$

${ }^{26} \mathrm{http}: / /$ www.loc.gov/standards/mods/userguide/abstract.html, last accessed 10 December 2015.

$27 \mathrm{http}: / /$ www.loc.gov/standards/mods/userguide/tableofcontents.html, last accessed 10 December 2015 
For long tables of contents, the Repository supports the inclusion of paragraphs and line breaks.

When creating XML metadata, \&\#xD; may be used to create a carriage return, while $\& \# x A ;$ will create a line break. The inclusion of two carriage returns or line breaks consecutively, for example $\& \# x A ; \& \# x A$; will create a paragraph break.

\section{Label Note 28 \\ Metadata element <mods: note $>$ or \\ $<$ mods:physicalDescription> \\ $<$ mods: note> \\ $</$ mods:physicalDescription $>$}

Definition

General textual information relating to a resource.

$<$ note $>$ is used for information that is not encoded in another, more specific MODS element.

Format of content Free text. Each note should be entered in a separate <mods: note> element and the note given a type value if possible.

Obligation

Mandatory if $<$ mods: note/ $>$, or $<$ mods:tableofContents $/>$, or $<$ mods:physicalDescription $><$ mods: note $/></$ mods: physical Description> not used

Repeatable Yes

Values (examples) <mods:physicalDescription>

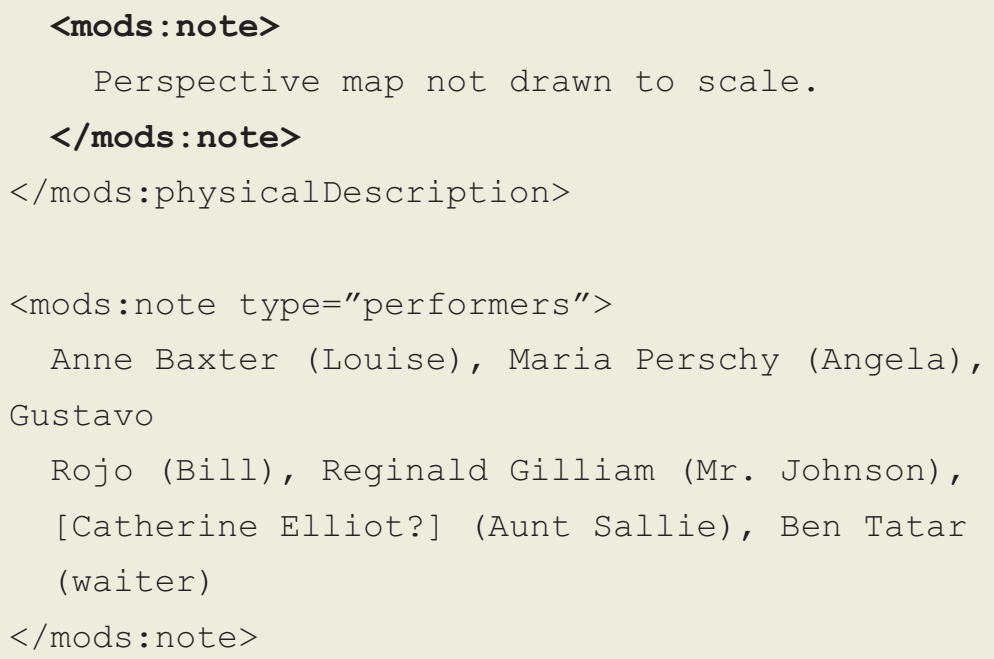

28 http://www.loc.gov/standards/mods/userguide/note.html, last accessed 10 December 2015. 
For long Notes, the Repository supports the inclusion of paragraphs and line breaks.

When creating XML metadata, $\& \# \times D$; may be used to create a carriage return, while $\& \# x A$; will create a line break. The inclusion of two carriage returns or line breaks consecutively, for example \&\#xA; \&\#xA; will create a paragraph break.

Notes relating to physical description aspects of a resource should be recorded in the $<$ mods : note $>$ subelement of $<$ mods: physicalDescription ${ }^{29}$.

Label

Metadata Element

Definition

Format of content

Obligation

Repeatable

Values (examples)

\section{Access Condition ${ }^{30}$}

$<$ mods:accesscondition>

Information about restrictions imposed on access to and use of a resource.

Free text

Mandatory

Yes

<mods:accesscondition type="use and reproduction">

<copyrightmD: copyright

copyright.status= "copyrighted" $>$

<copyrightmD:rights.holder>

Copyright Radio na Gaeltachta.

$</$ copyrightMD:rights.holder

<copyrightMD: general.note>

This work is licensed under a Creative Commons

Attribution-NoDerivs 3.0 Ireland License.

Please use the following attribution when

citing this work: Copyright Radio na

Gaeltachta, digital surrogate created by the

DRI NUI Galway Demonstrator Project

</copyrightMD:general.note>

$</$ copyrightmD: copyright $>$

$</$ mods:accessCondition $>$

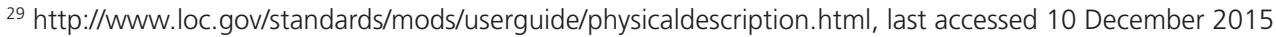

$30 \mathrm{http}: / / w w w . l o c . g o v / s t a n d a r d s / m o d s / u s e r g u i d e / a c c e s s c o n d i t i o n . h t m l$, last accessed 10 December 2015. 


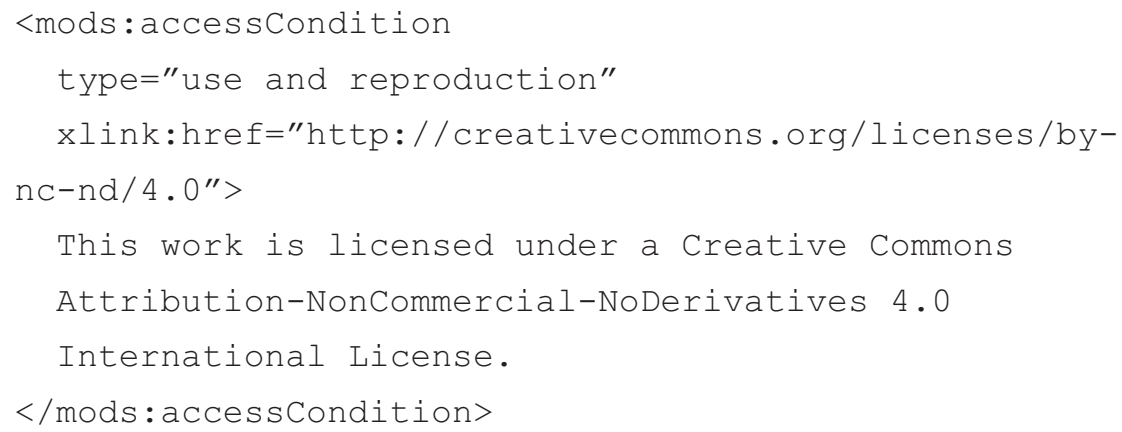

Note

manner,
There are no subelements defined in MODS for $<$ mods:accesscondition>. However, this element is extensible to allow for the use of an established XML schema outside of MODS for the information, e.g. the CDL Copyright schema. ${ }^{31}$ When used in this $<$ mods:accesscondition> becomes a container element.

DRI requires the use of the type attribute with a value of "use and reproduction" as mandatory to indicate the type of restrictions (or lack thereof) on use of the resource and/or restrictions on access to the material. While there is no controlled list of values for the type attribute for <mods: accesscondition>, suggested values are "restriction on access" (if the information is about restrictions imposed on access to the described materials) and "use and reproduction" (if the information refers to terms governing the use of the materials after access has been provided).

One use of <mods: accesscondition $>$ is to indicate rights relating to access and use of a resource, particularly digital resources. The audience for such rights information is the end user, so rights information should be as free of legalese and technical jargon as possible. State clearly any restrictions on use of the resource, including explicitly mentioning lack of copyright restrictions when the resource is in the public domain. Also provide contact information for use by end users who wish to pursue required permissions for publication, exhibit, or other types of dissemination.

A link may be supplied in lieu of or in addition to the content. If, for example, you maintain rights information relating to specific resources on a website, you may wish to provide a URL for that website in lieu of a textual rights statement. When doing so, you should provide enough textual explanation, along with the URL, to make the purpose of the URL clear to end users. In addition, if you are using a specific type of licence, such as Creative Commons, the text and link to that licence should be included here. 


\section{Label}

Metadata element

Definition

\section{Format of content}

Obligation

Repeatable

Values (examples)
Type of Resource ${ }^{32}$

<mods: typeofResource>

A term that specifies the characteristics and general type of content of the resource.

Controlled vocabulary MODS values for $<$ typeofResource> 33

Mandatory

Yes

<mods: typeofResource>

moving image

$</$ mods : typeofResource $>$

$<$ mods: typeofResource>

cartographic

$</$ mods: typeofResource $>$

<mods: typeofResource>

sound recording non-musical

$</$ mods: typeofResource $>$

<mods:typeofResource collection="yes" />

Notes "yes", should be used if describing a collection resource ${ }^{34}$. This attribute is only present if this is the case.

Information in <mods: typeofResource> is about the original item. For example, in the case of a digitised photograph,

$<$ mods: typeofResource> would apply to the analogue original; in borndigital materials, it would apply to the original digital format.

\footnotetext{
$32 \mathrm{http}: / / \mathrm{www}$. loc.gov/standards/mods/userguide/typeofresource.html, last accessed 10 December 2015

${ }^{33} \mathrm{http}: / / \mathrm{www}$. loc.gov/standards/mods/userguide/typeofresource.html, last accessed 10 December 2015.

$34 \mathrm{http}: / /$ www.loc.gov/standards/mods/v3/mods-collection-description.html, last accessed 10 December 2015.
} 


\section{Recommended Elements}

\begin{tabular}{|c|c|}
\hline Label & Subtitle 35 \\
\hline Metadata element & $\begin{array}{l}<\text { mods:titleInfo> } \\
\quad<\text { mods:title> } \\
\quad<\text { mods:subTitle> } \\
\text { </mods:titleInfo> }\end{array}$ \\
\hline Definition & $\begin{array}{l}\text { A word, phrase, character, or group of characters that contains the } \\
\text { remainder of the title information after the title proper. } \\
<\text { mods: titleInfo }>\text { is a container element that contains all subelements } \\
\text { related to title information. Data content is contained in subelements. Do } \\
\text { not include punctuation intended to delineate parts of titles that are } \\
\text { separated into subelements of }<\text { mods: titleInfo>. }\end{array}$ \\
\hline Format of content & Free Text \\
\hline Obligation & Recommended \\
\hline Repeatable & Yes \\
\hline Values (examples) & $\begin{array}{l}\text { <mods:titleInfo> } \\
\text { <mods:title>The Age of Migrating Ideas</mods:title> } \\
\text { <mods:subTitle> } \\
\quad \text { Early Medieval Art in Northern Britain and } \\
\quad \text { Ireland } \\
\text { </mods:subTitle> } \\
\text { </mods:titleInfo }>\end{array}$ \\
\hline Label & Language $^{36}$ \\
\hline Metadata element & $<$ mods: language $>$ \\
\hline Definition & $\begin{array}{l}\text { A designation of the language in which the content of a resource is } \\
\text { expressed. }\end{array}$ \\
\hline Format of Content & $\begin{array}{l}\text { Language codes should be formatted according to ISO } 639^{37} \\
\text { or RFC5646 }\end{array}$ \\
\hline Obligation & Recommended \\
\hline Repeatable & Yes \\
\hline Values (examples) & <mods: language> \\
\hline
\end{tabular}

${ }^{35}$ http://www.loc.gov/standards/mods/userguide/titleinfo.html\#subtitle, last accessed 10 December 2015.

${ }^{36} \mathrm{http}: / / \mathrm{www}$. loc.gov/standards/mods/userguide/language.html, last accessed 10 December 2015

${ }^{37} \mathrm{http}: / /$ www.loc.gov/standards/iso639-2/php/code_list.php, last accessed 10 December 2015.

$38 \mathrm{http} / / /$ tools.ietf.org/html/rfc5646, last accessed 10 December 2015. 


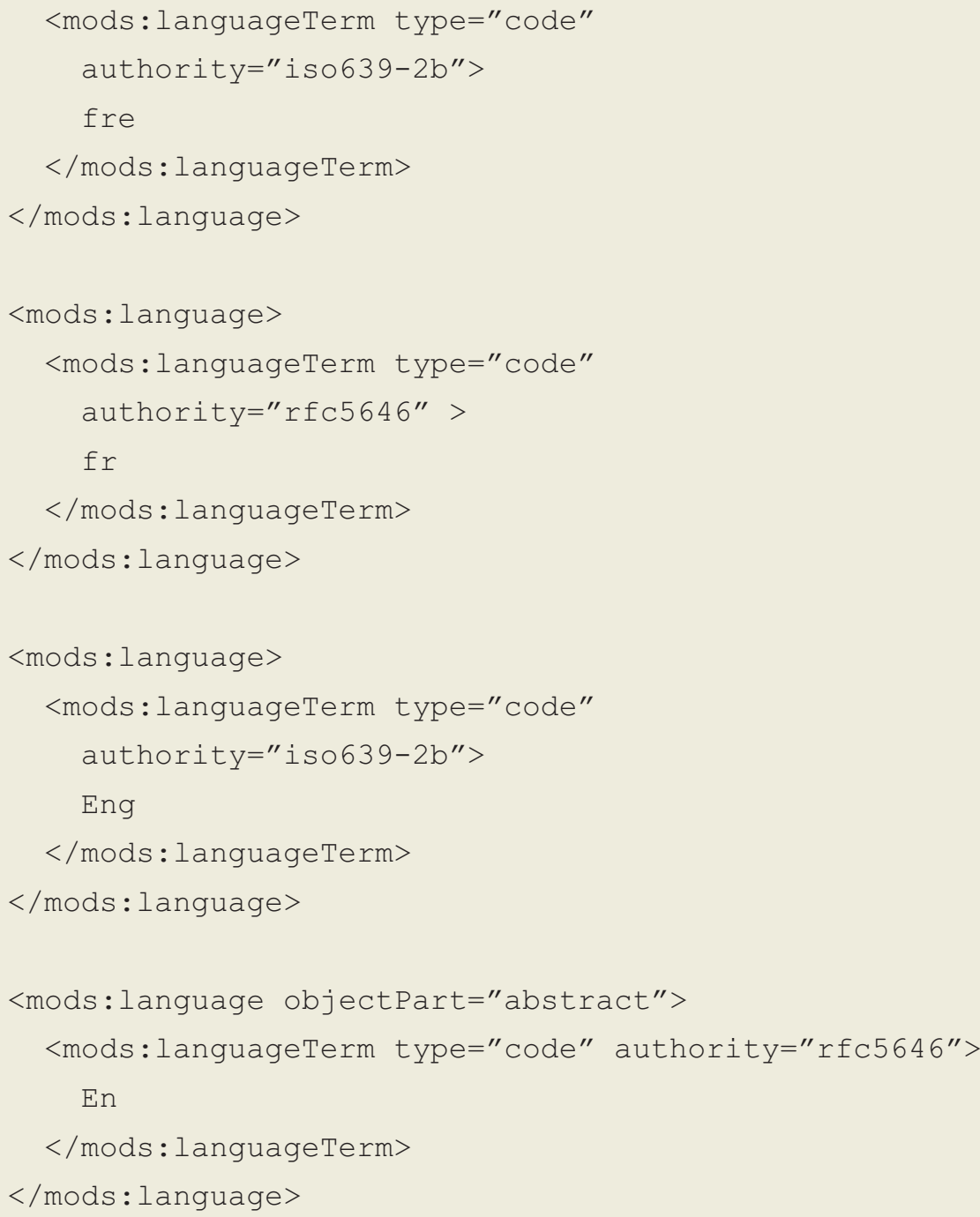

Notes

$<$ mods: language $>$ is a container element; the actual language values are recorded in the sub-element <mods: languageTerm $>$. The type attribute indicates whether the language is expressed in a coded or textual form.

If the content of the resource is in more than one language, the object Part attribute for <mods: language $>$ is used to indicate which language is used for each part of the resource, and the <mods: language> element is repeated.

If you are not using the language code recommended above, the language will not be indexed. 
Regardless of the vocabulary used, all language codes will be indexed as three-letter ISO 639-2 codes. For example, items with language codes "en", "eng", "en_IE", "en_US" or "en_UK" will be recognised as using a common language and indexed together as "eng".

The language code will also be converted into English and Irish and indexed. So a search for "english" will find records containing "en", "eng", "en_IE" etc. as their language.

\section{Label \\ Metadata element \\ Definition}

Format of content

\section{Obligation}

Repeatable

Values (examples)

\section{Related Item ${ }^{39}$}

$<$ mods:relatedItem>

Information that identifies other resources related to the one being described.

It can be used to describe a constituent part of a multi-part resource which is considered intellectually one object (e.g. a book with several chapters, a painting consisting of several panels).

All other MODS elements can appear as subelements of $<$ mods: relatedItem>.

Free text, bibliographic citation, URL.

$<$ mods: relatedItem> includes a designation of the specific type of relationship as a value of the "type" attribute. This is a controlled list of types enumerated in the schema, including, for instance, 'original' and 'isReferencedBy' ${ }^{40} \mathrm{DRI}$ recommends that users follow the Digital Library Federation / Aquifer Implementation Guidelines for Shareable MODS Records ${ }^{41}$ as they apply to the mods: relatedItem/> element, which make type a required attribute..$^{42}$

Recommended

Yes

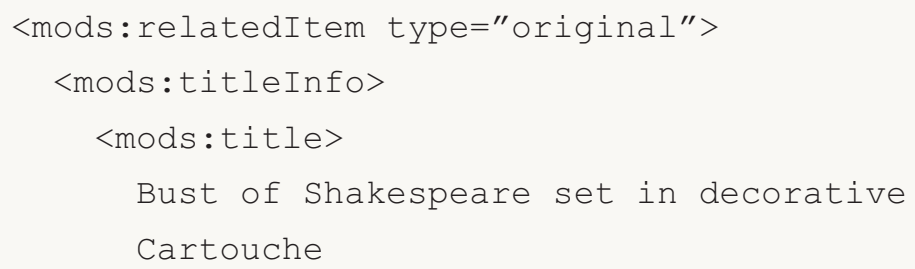




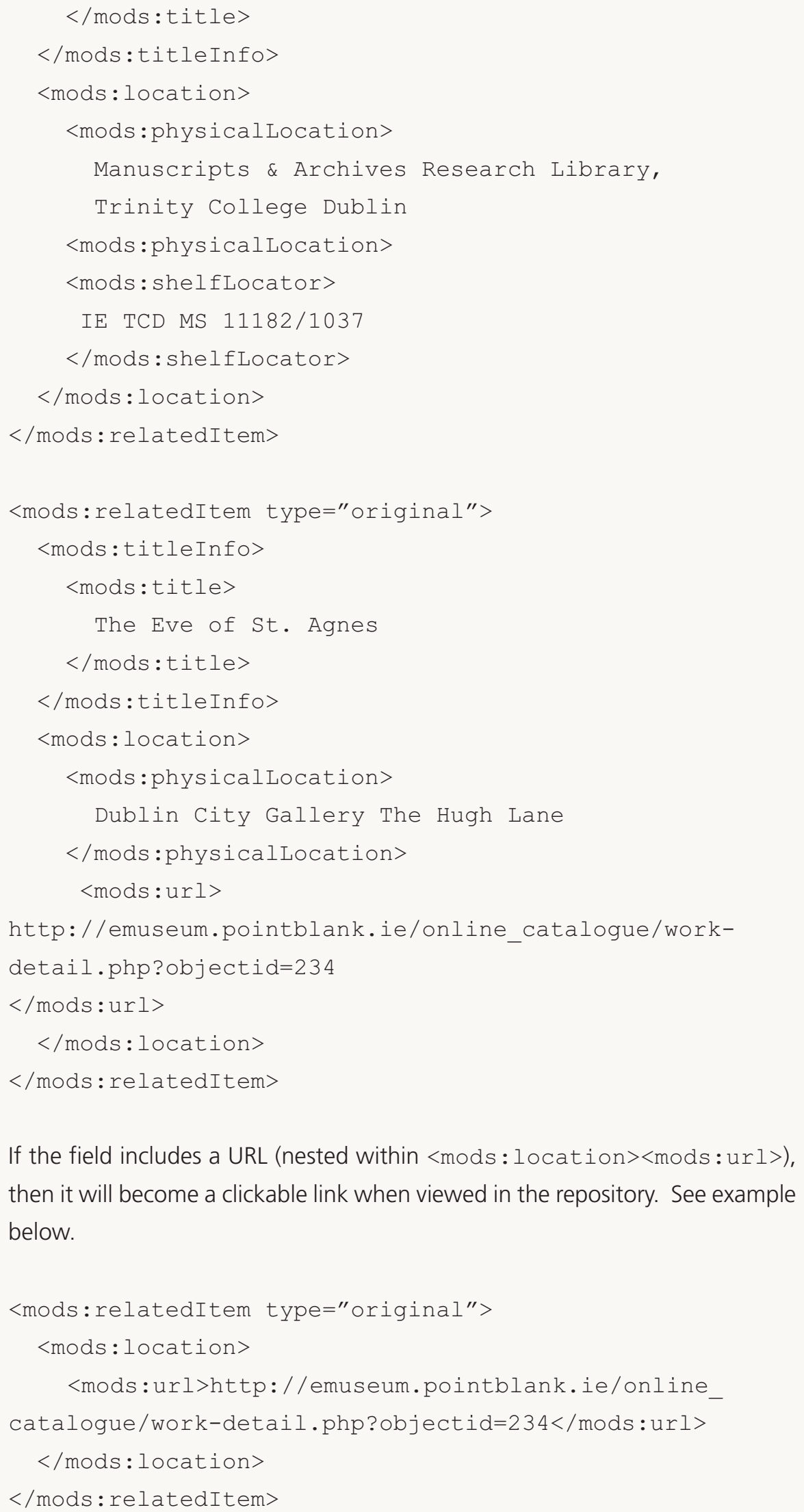

If the field includes a URL (nested within $<$ mods: location $>\langle$ mods: url $>$ ), then it will become a clickable link when viewed in the repository. See example below.

\section{Notes}




\begin{tabular}{|c|c|}
\hline Label & Subject: Topic ${ }^{43}$ \\
\hline Metadata element & $\begin{array}{l}<\text { mods: subject }> \\
\quad<\text { mods: topic }> \\
</ \text { mods: subject }>\end{array}$ \\
\hline Definition & 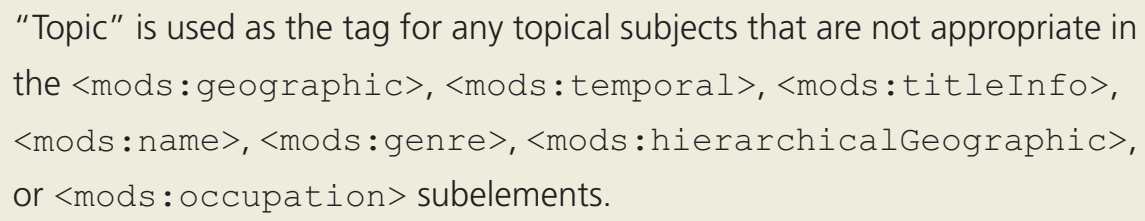 \\
\hline Format of content & $\begin{array}{l}\text { Free text. Use of controlled vocabularies recommended: } \\
\text { Irish Public Service Thesaurus }{ }^{44} \\
\text { HASSET Keywords }{ }^{45} \\
\text { Library of Congress Subject Headings }{ }^{46}\end{array}$ \\
\hline Obligation & Recommended \\
\hline Repeatable & Yes \\
\hline Values (examples) & $\begin{array}{l}<\text { mods: subject authority="lcsh" }> \\
\quad<\text { mods: topic }>\text { Musicology }</ \text { mods: topic }> \\
</ \text { mods: subject }>\end{array}$ \\
\hline Notes & $\begin{array}{l}<\text { mods: subject authority= "ipst" }> \\
\quad<\text { mods: topic>cultural heritage }</ \text { mods: topic } \\
</ \text { mods: subject }> \\
\text { If uncontrolled keywords or subject terms are included, then the } \\
\text { authority attribute should not be used. }\end{array}$ \\
\hline Label & Subject: Name ${ }^{47}$ \\
\hline Metadata element & $\begin{array}{l}<\text { mods: subject }> \\
\quad<\text { mods: name }> \\
</ \text { mods: subject }>\end{array}$ \\
\hline Definition & $\begin{array}{l}\text { The }<\text { mods : name }>\text { sub-element for }<\text { mods : subject }>\text { includes a name } \\
\text { used as a subject. }\end{array}$ \\
\hline Format of content & $\begin{array}{l}\text { Free text. Use of controlled vocabularies recommended: } \\
\text { Getty Union List of Artists Names }{ }^{48} \\
\text { Dictionary of Irish Biography }{ }^{49} \\
\text { Library of Congress Subject Headings }{ }^{50}\end{array}$ \\
\hline
\end{tabular}

\footnotetext{
${ }^{43} \mathrm{http}: / /$ www.loc.gov/standards/mods/userguide/subject.html\#topic, last accessed 10 December 2015.

${ }^{44} \mathrm{http}: / /$ www.gov.ie/webstandards/metastandards/pst/280602_html/index.htm, last accessed 10 December 2015.

${ }^{45} \mathrm{http}: / / \mathrm{www}$. esds.ac.uk/search/hassetsearch.asp, last accessed 10 December 2015.

${ }^{46} \mathrm{http} / / /$ id.loc.gov/search/?q=early+modern\&q=cs\%3Ahttp\%3A\%2F\%2Fid.loc.gov\%2Fauthorities\%2Fsubjects, last accessed 10 December 2015.

47 http://www.loc.gov/standards/mods/userguide/subject.html\#name, last accessed 10 December 2015.

${ }^{48} \mathrm{http}: / /$ www.getty.edu/research/tools/vocabularies/ulan/, last accessed 10 December 2015.

${ }^{49} \mathrm{http}: / /$ dib.cambridge.org/, last accessed 10 December 2015.

${ }^{50} \mathrm{http}: / /$ id. loc.gov/search/?q=early+modern\&q=cs\%3Ahttp\%3A\%2F\%2Fid.loc.gov\%2Fauthorities\%2Fsubjects, last accessed 10 December 2015.
} 


\section{National Register for Archives ${ }^{51}$}

Personal, family and corporate names should be formatted according to the Irish Guidelines for Indexing Archives. ${ }^{52}$

Obligation Repeatable

Values (examples)

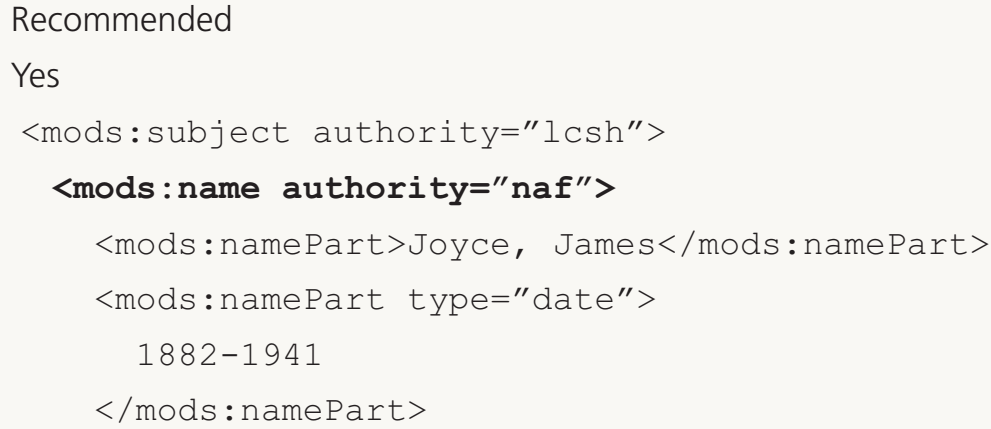

Notes

All subelements and attributes used under the top-level element $<$ mods: name> may be used. An authority attribute may also be used at this level if desired in addition to at the highest level (under $<$ mods : subject>). Equivalent to MARC 21 fields $600^{53}, 610^{54}, 611^{55}$. For Irish family names, such as Mary Choilm a' tSeaimpín, where Colm an tSeaimpín is a family identifier rather than a surname and cannot precede Mary, DRI suggests that the family identifier should follow the first name.

51 http://discovery.nationalarchives.gov.uk/, last accessed 10 December 2015.

$52 \mathrm{http}: / / w w w . l e a r n a b o u t a r c h i v e s . i e / \sim$ learnabo/images/documents/ARAlndexing.pdf, last accessed

10 December 2015.

${ }^{53} \mathrm{http}: / /$ www.loc.gov/marc/bibliographic/bd600.html, last accessed 10 December 2015.

54 http://www.loc.gov/marc/bibliographic/bd610.html, last accessed 10 December 2015.

${ }^{55} \mathrm{http}: / /$ www.loc.gov/marc/bibliographic/bd611.html, last accessed 10 December 2015. 


\section{Label}

Metadata Element

Definition

Format of content

Obligation

Repeatable

Values (examples)
Subject: Geographic ${ }^{56}$

<mods: subject>

$<$ mods: geographic>

$</$ mods: subject $>$

"Geographic" is used for geographic subject terms that are not parsed as hierarchical geographics. If the geographic name is part of a corporate body (i.e., United States. Senate), it is coded as <mods : name $>$, not $<$ mods : geo graphic $>$. <mods : geographic $>$ is equivalent to MARC 21 element $651^{57}$ and $6 X X X^{58}$ subfield $\$ z$.

Free text. If a controlled vocabulary is used, the source can be captured as an attribute of <mods : geographic> e.g. authority.

Recommended

Yes

$<$ mods: subject>

<mods: geographic>Ireland</mods: geographic>

$</$ mods: subject $>$

\section{Label}

Metadata element

Definition

Format of content

\section{Obligation}

Repeatable

Values (examples)

\section{Subject: Hierarchical Geographic ${ }^{59}$}

$<$ mods: subject>

<mods:hierarchicalGeographic>

$</$ mods: subject $>$

A geographic name given in a hierarchical form relating to the resource.

The <mods: hierarchicalGeographic $>$ is a wrapper element that contains a number of sub-elements.

Free text. Use of a controlled vocabulary is recommended. A good example of a controlled vocabulary for hierarchical geographic terms is the Getty Thesaurus of Geographic Names. ${ }^{60}$

Recommended

Yes

$<$ mods: subject authority=" $\operatorname{tgn} ">$

<mods: hierarchicalGeographic>

$<$ mods: country $>$ Ireland $</$ mods : country $>$

$<$ mods:province $>$ Leinster $</$ mods:province $>$

$<\operatorname{mods}$ : county $>$ Kildare $</$ mods : county $>$

$<$ mods: inhabitedPlace $>$ Maynooth

$</$ mods: inhabitedPlace $>$

\footnotetext{
${ }^{56} \mathrm{http}: / /$ www.loc.gov/standards/mods/userguide/subject.html\#geographic, last accessed 10 December 2015.

${ }^{57} \mathrm{http}: / /$ www.loc.gov/marc/bibliographic/bd651.html, last accessed 10 December 2015.

$58 \mathrm{http} / / / \mathrm{www}$. loc.gov/marc/bibliographic/, last accessed 10 December 2015.

$59 \mathrm{http}: / /$ www.loc.gov/standards/mods/userguide/subject.html\#hierarchicalgeographic, last accessed 10

December 2015.

${ }^{60} \mathrm{https}: / /$ www.getty.edu/research/tools/vocabularies/tgn/, last accessed 10 December 2015.
} 


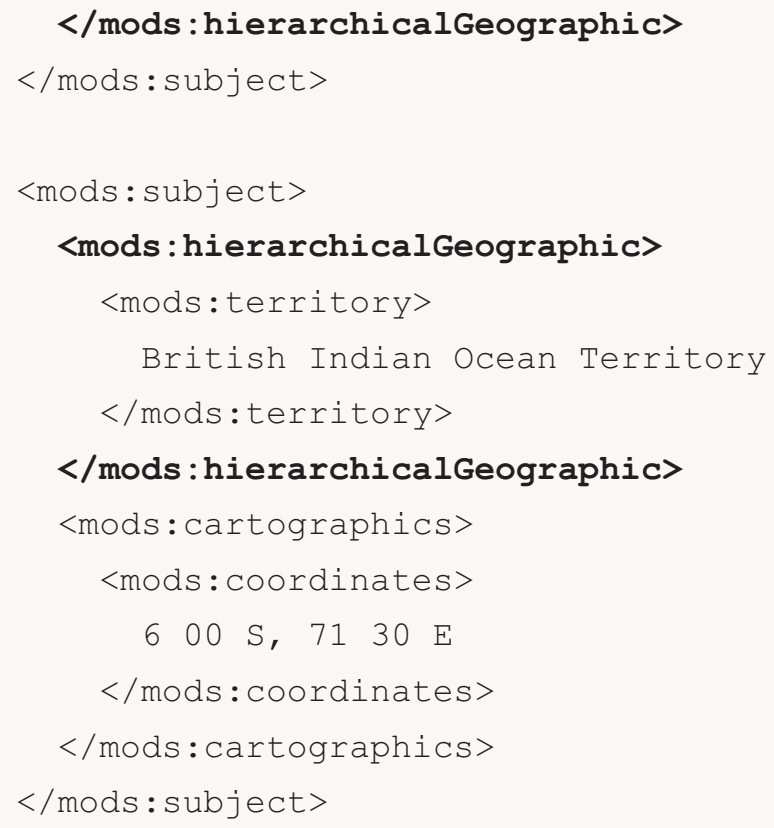

\section{Label}

Subject: Geographic Code ${ }^{61}$

Metadata Element <mods:subject>

<mods: geographicCode>

$</$ mods: subject $>$

Definition

A geographic area code associated with a resource. This subelement can only be used in conjunction with the <mods : geographic/> subelement, as part of the same <mods : subject/> element. The geographic code must represent the same entity as the term in the <mods: geographic $>$ sub-element.

Format of content Free text. Use of controlled vocabularies recommended e.g. ISO $3166^{62}$, MARC Code List for Geographic Areas ${ }^{63}$, MARC Code List for Countries. ${ }^{64}$

\section{Obligation}

Repeatable Recommended

Values (examples) Yes

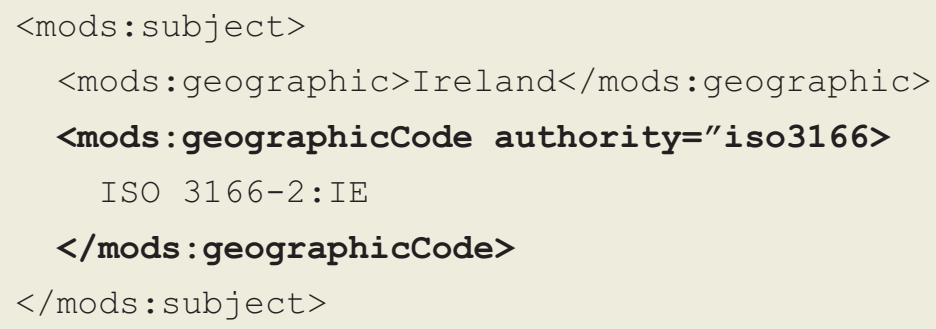

\footnotetext{
61 http://www.loc.gov/standards/mods/userguide/subject.html\#geographiccode, last accessed 10 December 2015

$62 \mathrm{http} / / / \mathrm{www}$.iso.org/iso/home/standards/country_codes.htm, last accessed 10 December 2015.

${ }^{63} \mathrm{http}: / / \mathrm{www}$. loc.gov/marc/geoareas/gacs_name.html, last accessed 10 December 2015.

${ }^{64} \mathrm{http}: / /$ loc.gov/marc/countries/countries_name.html, last accessed 10 December 2015.
} 


\section{Label \\ Metadata element \\ Subject: Cartographics ${ }^{65}$ \\ $<$ mods: subject>

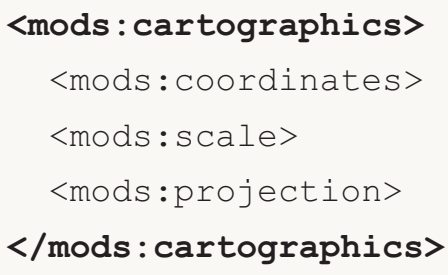

Definition

Format of content

Obligation

Repeatable

Values (examples) subelements. items. applicable.

Recommended

Yes

$<$ mods: subject $>$
Cartographic (maps or charts) data indicating spatial coverage.

The <mods : cartographics $>$ element is a container element that includes cartographic data indicating spatial coverage. Data content is entered in the

Free text. Recommended use of W3c Geo (Longlat) vocabulary. ${ }^{66}$

For the <mods : coordinates $>$ element, one or more statements may be supplied. If one is supplied, it is a point (i.e., a single location); if two, it is a line; if more than two, it is an $n$-sided polygon where $n=$ number of coordinates assigned. No three points should be co-linear, and coordinates should be supplied in polygon-traversal order.

$<$ mods:scale $>$ may include any equivalency statements, vertical scales, or vertical exaggeration statements for relief models and other three-dimensional

$<$ mods:projection> Includes the name of the projection and any associated information related to the properties of the projection, where

\section{<mods : cartographics>}

$<$ mods:coordinates $>$ E $72^{\circ}-\mathrm{E} 148^{\circ} / \mathrm{N} \quad 13^{\circ}-\mathrm{N} 18^{\circ}$

$</$ mods:coordinates $>$

$<$ mods:scale $>1: 22,000,000</$ mods:scale $>$

$<$ mods:projection>conic proj</mods:projection>

$</$ mods : cartographics $>$

$</$ subject $>$

65 http://www.loc.gov/standards/mods/userguide/subject.html\#cartographics, last accessed 10 December 2015.

${ }^{66} \mathrm{http}: / /$ www.w3.org/2003/01/geo/\#vocabulary, last accessed 10 December 2015. 

cartographic elements may be bound together with a geographic name (hierarchical or otherwise) within a $<$ mods : subject $>$ element.

\section{Label \\ Metadata element}

Definition

Format of content

\section{Obligation}

Repeatable

Values (examples)

Notes

\section{Subject: Tempora|69}

$<$ mods : subject>

\section{$<$ mods: temporal>}

$</$ mods:subject $>$

Used for chronological subject terms or temporal coverage.

May be expressed as a controlled subject term or as a structured date with an encoding attribute.

If a controlled subject term is used, indicate authority using the authority attribute at the <mods: subject> level. Controlled vocabulary: Library of Congress Subject Headings. ${ }^{70}$

If a structured date is used, indicate the formatting source using the encoding attribute. May be entered as free text or in structured form. In DRI, dates should be formatted according to w3cdtffi or ISO $8601^{72}$ to allow for the information to be searchable by date range, and displayed in the timeline visualisation tool.

Recommended

Yes

<mods: subject authority="lcsh">

<mods:temporal>World War, 1914-1918</mods:temporal>

$</$ mods: subject $>$

$<$ mods: subject>

<mods: temporal encoding="w3cdtf" point="start">

1914-07-28

$</$ mods : temporal $>$

<mods: temporal encoding="w3cdtf" point="end">

$1918-11-11$

$</$ mods : temporal $>$

$</$ subject $>$

For guidelines about the attributes of the <mods : temporal $>$ subelement, see the MODS User Guide ${ }^{73}$.

\footnotetext{
67 http://www.loc.gov/marc/bibliographic/bd034.html, last accessed 10 December 2015.

${ }^{68} \mathrm{http}: / /$ www.loc.gov/marc/bibliographic/bd255.html, last accessed 10 December 2015.

69 http://www.loc.gov/standards/mods/userguide/subject.html\#temporal, last accessed 10 December 2015

$70 \mathrm{http} / / /$ authorities.loc.gov/, last accessed 10 December 2015.

71 http://www.w3.org/TR/NOTE-datetime, last accessed 10 December 2015.

72 http://www.iso.org/iso/home/standards/iso8601.htm, last accessed 10 December 2015.

73 http://www.loc.gov/standards/mods/userguide/subject.html\#temporal, last accessed 10 December 2015.
} 


\section{uwu.dri.ie}

